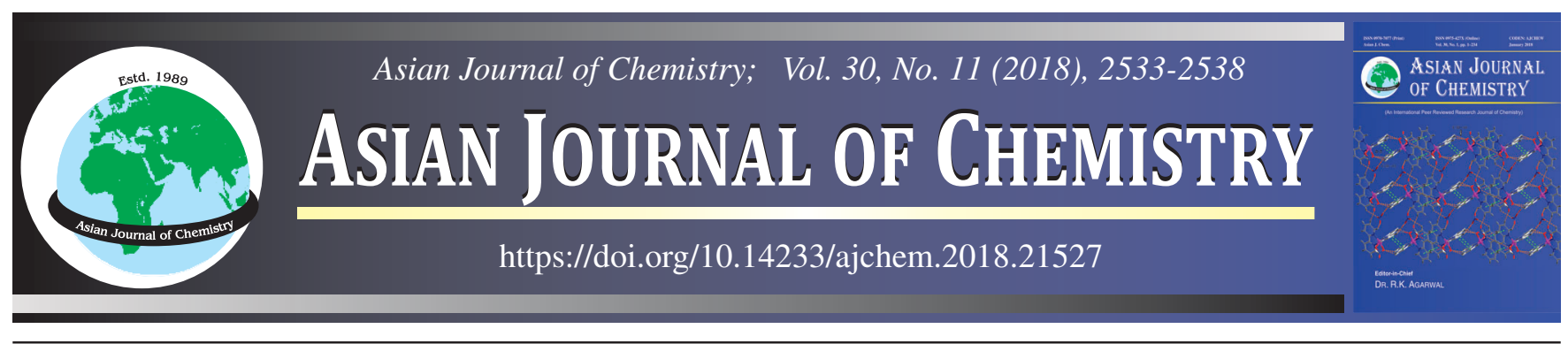

\title{
Photocatalytic Activity of Carbon Nanotubes Synthesized by Flame Fragments Deposition Method and Its Composites with $\mathrm{TiO}_{2}$
}

\author{
Asmaa H. Hammadi ${ }^{1}$, Abbas J. AtiYah ${ }^{2}$ and Falah H. Hussein ${ }^{1,3, *}$
}

${ }^{1}$ College of Pharmacy, University of Babylon, Hilla, Iraq

${ }^{2}$ Department of Chemistry, College of Science, University of Babylon, Hilla, Iraq

${ }^{3}$ Al-Mustaqbal University College, Babylon, Iraq

*Corresponding author: E-mail: abohasan_hilla@yahoo.com

Received: 18 June 2018;

Accepted: 5 August 2018;

Published online: 27 September 2018;

AJC-19107

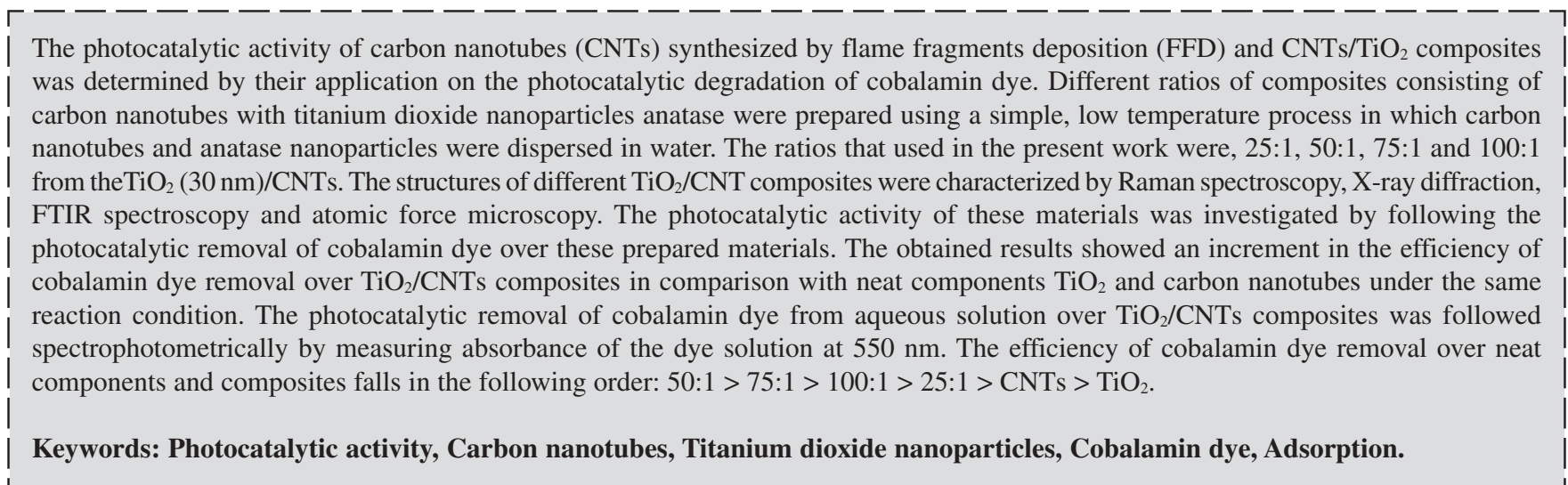

\section{INTRODUCTION}

Carbon nanotube is rolled up from one or more graphene sheets concentrically [1]. Depending on the number of graphite layers, carbon nanotubes are classified as single-wall carbon nanotubes (SWCNTs), double-wall carbon nanotubes (DWCNTs) or multi-wall carbon nanotubes (MWCNTs) [2]. Single-wall carbon nanotubes (SWNTs) are a unique class of material that have received an enormous amount of attention over recent years, because of their remarkable mechanical, thermal, electronic and optical properties [3,4]. Syntheses of carbon nanotubes by several methods includes arc discharge, laser ablation and chemical vapor deposition [5], yielding tubes of various diameter and length distributions [6].

Carbon nanotubes are sub-atomic scale containers of graphitic carbons with remarkable electronic, mechanical and warm properties [7]. The synergistic impact of carbon nano- tubes on the action of composite impetus can be clarified as far as its activity as adsorbents and a scattering agent. The advance CNTs conductive structure may encourage the division of the photograph created electron/gap sets at the $\mathrm{TiO}_{2}$-CNT interface prompting the quicker rates of photocatalytic oxidation and improvement in the proficiency of titanium dioxide [8].

Different techniques have been utilized for the planning of $\mathrm{TiO}_{2}-\mathrm{CNTs}$ composites. For the most part, $\mathrm{TiO}_{2}$ is covered on the surface of the carbon nanotube. The composites can be set up by different methods which incorporate sol-gel, impregnation, electro-turning, electrophoretic statement, compound vapor testimony and aqueous method [9-11]. $\mathrm{TiO}_{2}-\mathrm{CNTs}$ composite material have been appearing to expand the rodent of photograph reactant oxidation of toxins [12]. The conductivity structure of carbon nanotube platforms may encourage the detachment of the photograph created (e-h) pairs at $\mathrm{TiO}_{2}$-CNTs interface prompting the quicker rates of photograph synergist oxidation [13].

This is an open access journal, and articles are distributed under the terms of the Creative Commons Attribution-NonCommercial 4.0 International (CC BY-NC 4.0) License, which allows others to copy and redistribute the material in any medium or format, remix, transform, and build upon the material, as long as appropriate credit is given and the new creations are licensed under the identical terms. 
Different applications and difficulties for these composite materials are accounted for carbon nanotube-anatase titanium dioxide $\mathrm{CNT} / \mathrm{TiO}_{2}$ composite [14]. Recently, $\mathrm{CNTs} / \mathrm{TiO}_{2}$ composites have been attracting much care because of their excellent properties, including electrical properties, chemical and thermal stability, high adsorption capacity and high aspect ratio $[8,15,16]$. The applications of $\mathrm{TiO}_{2} / \mathrm{CNTs}$ composites for the big problem of pollutions obligation to their highest capability to behavior electrons and adsorb hydrophobic organic pollutants, barely adsorbed by $\mathrm{TiO}_{2}$ nanoparticles themselves [15]. In this paper, we reported the photoactivity of CNTs/ $\mathrm{TiO}_{2}$ anatase (nanopar-ticle) composite on removal of cobalamin (m.f. $\mathrm{C}_{63} \mathrm{H}_{88} \mathrm{~N}_{14} \mathrm{PCo}$ ) and compared the adsorption capacity of $\mathrm{TiO}_{2}, \mathrm{CNTs}$ and $\mathrm{CNTs} / \mathrm{TiO}_{2}$ composite.

\section{EXPERIMENTAL}

Cobalamin dye (m.f. $\mathrm{C}_{63} \mathrm{H}_{88} \mathrm{~N}_{14} \mathrm{PCo}$ ) was purchased from Sigma having purity $<98.5 \%$. Titanium dioxide nanoparticles $\left(\mathrm{TiO}_{2}\right)$ anatase $(10-30 \mathrm{~nm})$ purities $99 \%$ from Sky Spring Nanomaterials Inc. Acetone from S.D. Fine-Chem. Ltd., India with purities $99 \%$ and hydrogen peroxide was purchased from Barcelona, Spain in $30 \%$ by weight. The $\mathrm{N}_{2}$ gas used in purities 99.999\% from Emirates industrial gases.

Synthesis of carbon nanotubes: In this part, carbon nanotubes (CNTs) were synthesized according to flame fragments deposition method using a homemade chamber instrument constructed for synthesized of carbon nanotubes (CNTs) from Iraqi natural gas as carbon source. The instrument consists of nine collection centers at the top position where is embedded in each position. One of them is used without catalyst and the other eight with different types of catalysts. Rümmeli et al. [17] synthesized of carbon nanotubes without catalysts and with catalysts $\left(\mathrm{Fe}^{2+}: \mathrm{Mo}: \mathrm{Mg}\right)$. The catalysts $\left(\mathrm{Fe}^{2+}: \mathrm{Mo}: \mathrm{Mg}\right)$ ratio (1:0.1:11). The catalyst was prepared by using combustion methods as in the literature [18]. An aqueous solution consisting of $\mathrm{FeSO}_{4}$ and ammonium molybdate $\left(\mathrm{NH}_{4}\right)_{6} \cdot \mathrm{Mo}_{7} \cdot \mathrm{O}_{24} \cdot 4 \mathrm{H}_{2} \mathrm{O}$ were mixed together with a weight ratio of Fe:Mo equal to 1:0.1 and with stirring for $1 \mathrm{~h}$. The bimetallic solution was introduced to $\mathrm{Mg}\left(\mathrm{NO}_{3}\right)_{2} \cdot 6 \mathrm{H}_{2} \mathrm{O}$ solution and $1 \mathrm{~g}$ of citric acid with a weight ratio of $\mathrm{Fe}: \mathrm{Mg}:$ Mo equal to 1:11:0.1, respectively, followed by sonication for $1 \mathrm{~h}$. The solution was stirred for $10 \mathrm{~h}$ with an increase in temperature to $60^{\circ} \mathrm{C}$ in order to dry the mixture. The powder was treated thermally at $150^{\circ} \mathrm{C}$ for $10 \mathrm{~h}$ in nitrogen atmosphere by using tube furnaces and then ground in a mortar to remove any agglomerate that may have formed during the final composition of the trimettalic catalyst. After the crucibles were fogged by catalyst, synthesized of carbon nanotubes. The carbon nanotubes were characterized using the X-ray diffraction (XRD) and Raman analysis.

Purification of carbon nanotubes: The purification of synthesized carbon nanotubes was peformed via oxidation with $\mathrm{H}_{2} \mathrm{O}_{2}$ then treated with acetone using separation funnel. Carbon nanotubes $(100 \mathrm{mg})$ was dispersed in $50 \mathrm{~mL}$ of $\mathrm{H}_{2} \mathrm{O}_{2}$ and sonicated for $1 \mathrm{~h}$. The mixture was left in the refrigerator at $4{ }^{\circ} \mathrm{C}$ for $24 \mathrm{~h}$, after that the solution allowed to reach room temperature, then heated gradually to $50^{\circ} \mathrm{C}$ until all hydrogen peroxide removed completely. Finally, the sample was washed with deionized water and dried at $80{ }^{\circ} \mathrm{C}$ for $4 \mathrm{~h}$. After that addition of $15 \mathrm{~mL}$ acetone to the dry sample and sonicated for $15 \mathrm{~min}$. The suspension was then centrifuged for $15 \mathrm{~min}$. The separated carbon nanotubes were then calcined at $275^{\circ} \mathrm{C}$ for $2 \mathrm{~h}$ and finally characterized using X-ray diffraction (XRD) and Raman spectroscopy.

Functionalization of carbon nanotubes: Functionalization of carbon nanotubes is an important step that can be used in order to introduce some functional groups into the surface and improve its surface properties. In this context, carbon nanotubes $\left(100 \mathrm{mg}\right.$ ) were suspended in $75 \mathrm{~mL} \mathrm{H}_{2} \mathrm{O}_{2}$ (30\% weight) in a $100 \mathrm{~mL}$ round bottom flask equipped with a condenser and the dispersion was heated to $80^{\circ} \mathrm{C}$ at reflux for overnight.

After the reflux, the suspension containing carbon nanotubes and $\mathrm{H}_{2} \mathrm{O}_{2}$ was heated to $50{ }^{\circ} \mathrm{C}$ with irradiation under an (UV) lamp for $5 \mathrm{~h}$ to dry the mixture. The oxidation of carbon nanotubes surface is very important to produce the composite. The homogeneous diffusion of O-CNTs takes place in distilled water due to formation of hydrogen bonding. They formed functioned O-CNTs was investigated using FTIR.

Synthesis $\mathrm{TiO}_{2} / \mathrm{CNTs}$ composites: Different ratios from titanium dioxide nanoparticles $\left(\mathrm{TiO}_{2}\right)$ anatase/CNTs composite structures were prepared by a simple evaporation and drying process. To prepare $\mathrm{TiO}_{2} / \mathrm{CNTs}$ composite, approximately 10 $\mathrm{mg}$ carbon nanotubes was dispersed in $150 \mathrm{~mL}$ of distilled water and sonicated for $15 \mathrm{~min}$, titanium dioxide powder was added to the carbon nanotubes suspension with continuous stirring. After that it was sonicated for $10 \mathrm{~min}$, the suspension containing carbon nanotubes and $\mathrm{TiO}_{2}$ particles was heated to $80^{\circ} \mathrm{C}$ with flushing $\mathrm{O}_{2}$ gas in solution to accelerate the evaporation of water. Then, the composite was dried overnight in an oven at $104{ }^{\circ} \mathrm{C}$ to avoid oxidation of the carbon nanotubes. Different composites were prepared using different ratios of $\mathrm{TiO}_{2}(30$ $\mathrm{nm}$ ) and carbon nanotubes. These mass ratios were 25:1, 50:1, 75:1 and 100:1. The obtained composites were investigated using (XRD) and atomic force microscopy (AFM).

Activity of pristine $\mathrm{TiO}_{2}$, carbon nanotubes and anatase $\mathrm{TiO}_{2}$ : The photocatalytic activity of pristine CNTs and $\mathrm{TiO}_{2}$ and composites of different ratios 25:1, 50:1, 75:1 and 100:1 to form $\mathrm{TiO}_{2} / \mathrm{CNTs}$ was investigated by following the decolorization of cobalamin dye in an aqueous solution of $100 \mathrm{~mL}$ (40 ppm) under UV light. Aqueous suspensions of CNT and/ or $\mathrm{TiO}_{2}$ containing cobalamin dye in a beaker under continuous stirring under irradiation with UV light at wavelength of 365 $\mathrm{nm}$. The required amount of the catalyst was suspended in $100 \mathrm{~mL}$ of aqueous solution of cobalamin. After illumination, $2 \mathrm{~mL}$ was taken from the reaction suspension, centrifuged at $6000 \mathrm{rpm}$ for $15 \mathrm{~min}$ and then filtered to remove the particles. The second centrifugation was found necessary to remove fine particles of carbon nanotubes, $\mathrm{TiO}_{2}, 25: 1,50: 1,75: 1$ and 100:1 from $\mathrm{TiO}_{2}(30 \mathrm{~nm}) / \mathrm{CNTs}$. The absorbance of cobalamin was then determined at $550 \mathrm{~nm}$.

\section{RESULTS AND DISCUSSION}

Activity of $\mathrm{CNTs} / \mathrm{TiO}_{2}$ composite: The photocatalytic activity of both neat of $\mathrm{TiO}_{2}, \mathrm{CNTs}$ and the synthesized composites was investigated by following the photocatalytic removal of cobalamin dye $(40 \mathrm{ppm})$ from aqueous solutions under irradiation with UV light. Fig. 1 shows the changes in removal 


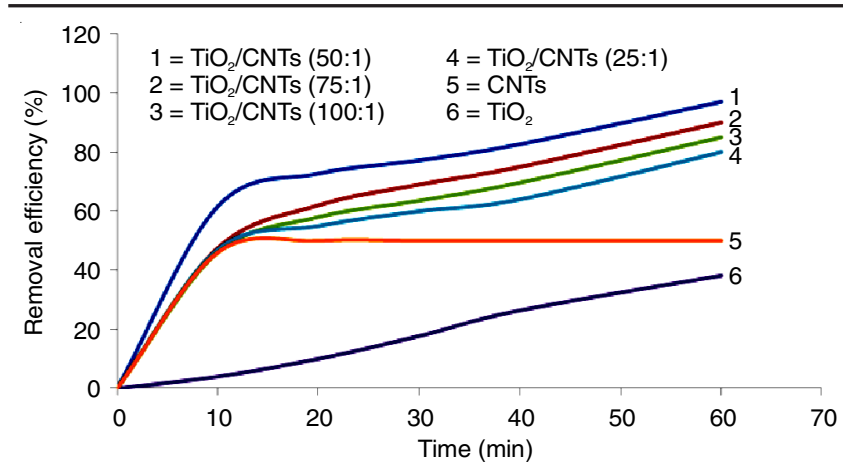

Fig. 1. Effect of time of adsorption on the removal efficiency of CA dye (40 ppm) over neat $\mathrm{TiO}_{2}, \mathrm{CNT}$ s and $\mathrm{TiO}_{2} / \mathrm{CNT}$ s composites

efficiency of the cobalamin dye in aqueous solution upon irradiation over $\mathrm{CNTs} / \mathrm{TiO}_{2}$ composite in different ratios. The results indicate that carbon nanotubes can enhance adsorption properties of $\mathrm{TiO}_{2}$ anatase due to increase surface area of produced composites in comparison with neat components of used composites [19]. The obtained results are presented in Fig. 1.

The optimum removal efficiency was achieved with composite (50:1) around $97 \%$. The efficiency of photocatalytic degradation of cobalamin dye over other composites of $\mathrm{TiO}_{2} / \mathrm{CNTs}$ ratios $(75: 1,100: 1,25: 1)$ and neat $\mathrm{CNT}$ and $\mathrm{TiO}_{2}$ were around $90,86,80,50$ and $38 \%$, respectively. In general, the efficiency of dye removal over the used composites were more efficient than neat $\mathrm{TiO}_{2}$ and $\mathrm{CNTs}$ which indicated that all ratios of $\mathrm{TiO}_{2} /$ CNTs composites lead to enhance surface properties with increasing of specific surface area of the prepared composites. This can lead to improve catalytic activity of all the composites in comparison of neat components which leads to the separation of photogenerated electron-hole pairs and decrease of their recombination rate and thus display significantly enhanced photocatalytic activity for removal of cobalamin dye in aqueous solution under UV irradiation.

The results of cobalamin dye removal by adsorption onto different photocatalysts are presented in Fig. 2. From these results, it can be seen that there is a progressive increment in the efficiency of dye removal with time progressing. Besides that composites are more efficient than separated components in dye removal under the same adsorption conditions. For composite of $\mathrm{TiO}_{2} / \mathrm{CNT}$ s equilibrium adsorption is being achieved within $0.5 \mathrm{~h}$ for four prepared ratios of $\mathrm{TiO}_{2} / \mathrm{CNT}$ composites. When adsorption reaches equilibrium the efficiency of cobalamin adsorption onto composites and neat components fall in the following order: 50:1 > 75:1 > 100:1 > 25:1 > CNTs > $\mathrm{TiO}_{2}$. This result can be attributed to the improvement of catalytic properties and increment of specific surface area of the prepared composites in comparison with their single components. The carbon nanotubes can increase surface area for synthesized composites and then reduce the rate of electron-hole recombination on $\mathrm{TiO}_{2}$ by injecting conduction band electrons into to the surface of carbon nanotubes leading to reduced back electron transfer. This can lead to improve the total efficiency of photocatalytic activity of decolorization of cobalamin dye over the used composites.

Characterization of $\mathrm{TiO}_{2}, \mathrm{CNTs}$ and $\mathrm{TiO}_{2} / \mathrm{CNTs}$ composites: Fig. 3 shows the Raman spectra for carbon nanotubes. Three bands are observed at $1341 \mathrm{~cm}^{-1}$ (D), $1581 \mathrm{~cm}^{-1}$ (G) and

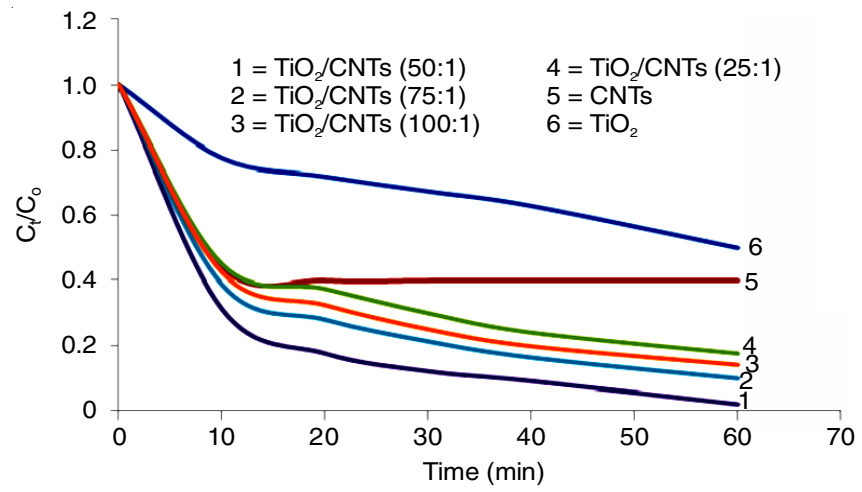

Fig. 2. Effect of time of adsorption on the relative concentration of cobalamin dye

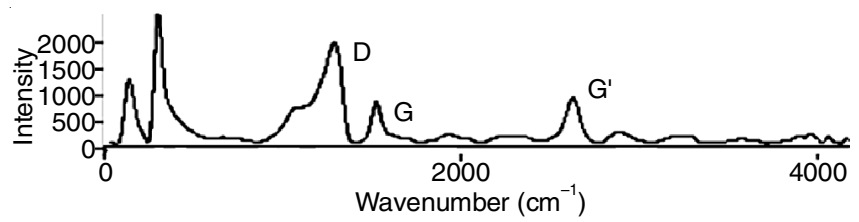

Fig. 3. Raman spectroscopy for CNTs after purification

$2700 \mathrm{~cm}^{-1}\left(\mathrm{G}^{\prime}\right)$. The peak at $1341 \mathrm{~cm}^{-1}$ in the spectrum for carbon nanotubes compare to D-band of confused graphitic carbon in carbon nanotubes. The peak at $1581 \mathrm{~cm}^{-1}$ in the spectrum for carbon nanotubes relates to G-band of graphitic carbon in carbon nanotubes while D- and G-groups show the nearness of crystalline graphite carbon in carbon nanotubes. The $\mathrm{G}^{\prime}$ band at 2700 $\mathrm{cm}^{-1}$ are sensitive to the freight exchanged between the nanotubes and the demote moiety [20].

Crystal structure of carbon nanotubes was investigated using XRD patterns using (Rigaku Rotalflex) (RU-200B) Xray diffractometer with $\mathrm{CuK} \alpha$ radiation $(\lambda=0.15405 \mathrm{~nm})$ with a Ni filter. The tube current was $100 \mathrm{~mA}$ with a tube voltage of $40 \mathrm{kV}$. XRD patterns were performed in range of $2 \theta$ between $10^{\circ}$ and $80^{\circ}$ with a scan rate of $5 \%$ min with a resolution in the $2 \theta$ scans was at $0.02^{\circ}$. XRD patterns for the synthesized carbon nanotubes are shown in Fig. 4, which shows the characteristic peaks at $24.56^{\circ}$ and $44.16^{\circ}$, these peaks are related to carbon nanotubes after purification. These results indicate that carbon nanotubes synthesized by flame fragments deposition are in good quality compared with that obtained by using chemical vapour deposition techniques [21].

The FTIR analysis was performed to confirm the presence of the introduced functional groups into the surface of CNTs

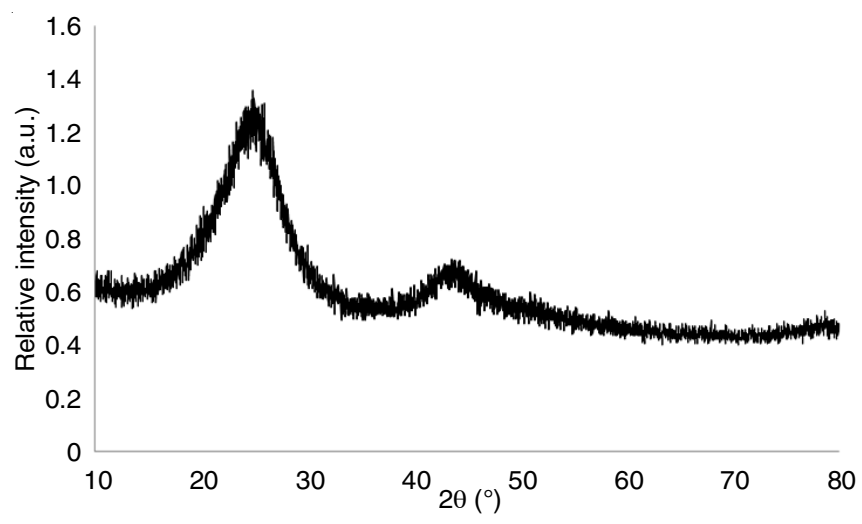

Fig. 4. XRD patterns for the synthesized CNTs 
after functionalization processes. Oxidation of CNTs with $\mathrm{H}_{2} \mathrm{O}_{2}$ (30\% weight) and UV-irradiation introduces some functional groups like-OH and-COOH. These surface groups are supportive to form interaction and chemical bonding between CNTs and $\mathrm{TiO}_{2}$ [22]. FTIR spectra of functionalized CNTs exhibits characteristic strong and broad bands between $3600-3173 \mathrm{~cm}^{-1}$, which can be assigned to $\mathrm{O}-\mathrm{H}$ stretching vibrations in $\mathrm{C}-\mathrm{OH}$ groups. The band between $1760-1690 \mathrm{~cm}^{-1}$ is related to $\mathrm{C}=\mathrm{O}$ stretching vibrations in carboxyl groups (Fig. 5) [23].

The surface morphology of synthesized CNTs was investigated using atomic force microscope (AFM). The obtained AFM images show filaments with length 1-1.5 $\mu \mathrm{m}$ and diameter around $0.5 \mu \mathrm{m}$, which appeared as bundles in $\mathrm{TiO}_{2} / \mathrm{CNTs}$ composite (ratio 50:1) filaments (Fig. 6). The CNTs bundles easily bend and wrap around anatase $\mathrm{TiO}_{2}$ particles, because of the weak van der Waals interaction between the CNTs in bundles [24].

The CNTs bundles which appear to be about $40 \mathrm{~nm}$ in diameter (Fig. 7a) while $\mathrm{TiO}_{2}$ particles show a diameter around $50 \mathrm{~nm}$ (Fig. 7b). The $\mathrm{TiO}_{2} / \mathrm{CNTs}$ composite with a ratio of 25:1 is lesser than different ratios 50:1 ,75:1 and 100:1 because of the large CNTs amount concludes that light did not reach to all particles (Fig. 7c) while the $\mathrm{TiO}_{2} / \mathrm{CNTs}$ composite with a ratio of 50:1 is greater than different ratios 25:1,75:1 and

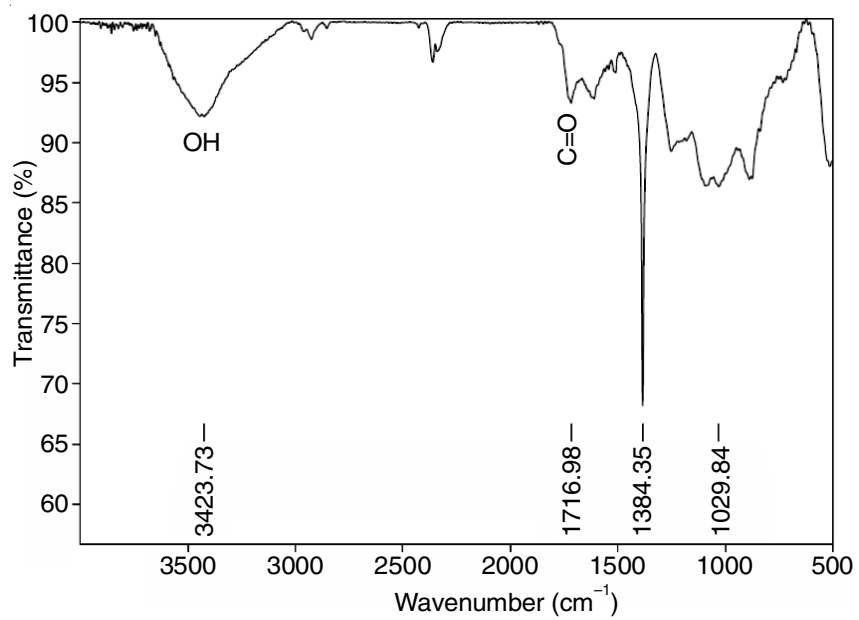

Fig. 5. FTIR spectra for functionalization of carbon nanotubes

100:1 might be due to the large diameter $50 \mathrm{~nm}$ (Fig. 7d). The ratios of 75:1 and 100:1 are lesser than ratio 50:1, so the surface area is reduced due to increased $\mathrm{TiO}_{2}$ amount (Fig 7e-f).

Fig. 8 shows the XRD patterns of $\mathrm{CNTs}_{2}, \mathrm{TiO}_{2}$ and CNTs/ $\mathrm{TiO}_{2}$ composite. The most intense peaks of CNTs agreed to the $24.56^{\circ}(002)$ reflection and $43.16^{\circ}(100)$ band, the peaks for $\mathrm{TiO}_{2}$ are $25.33^{\circ}(101), 37.88^{\circ}(004), 47.68^{\circ}(200), 54.14^{\circ}(105)$,

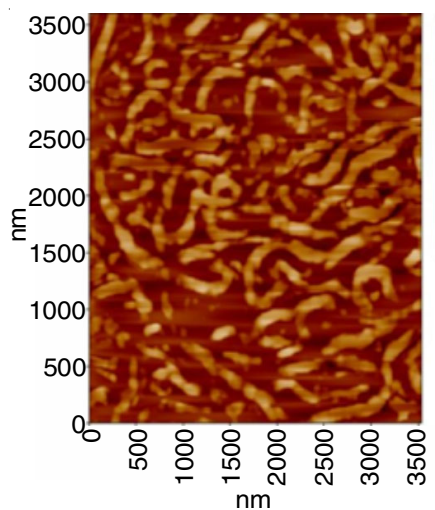

(a)

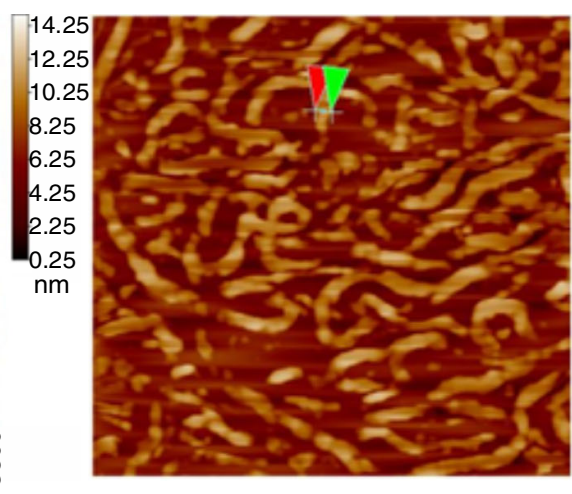

Fig. 6. AFM for synthesized CNTs

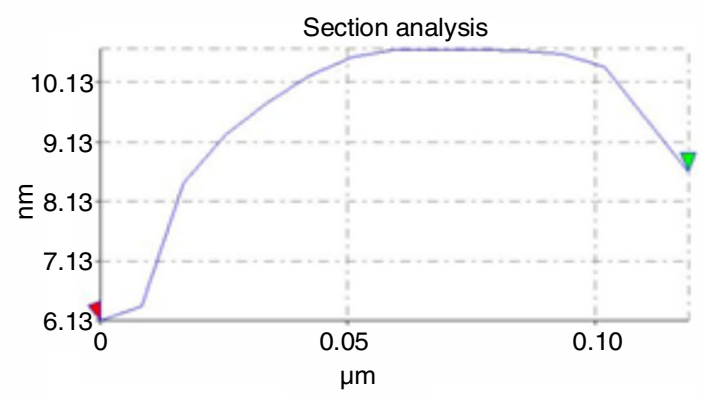

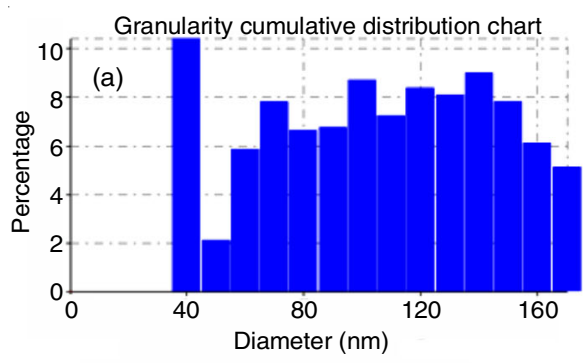

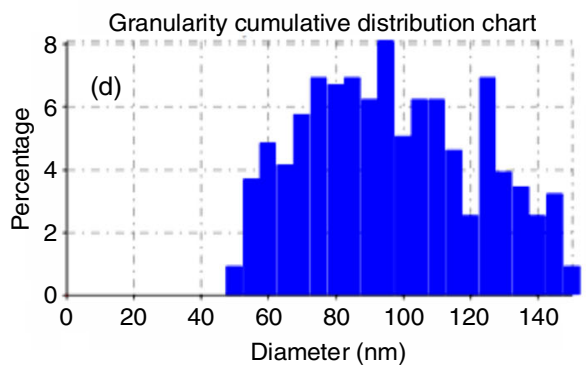

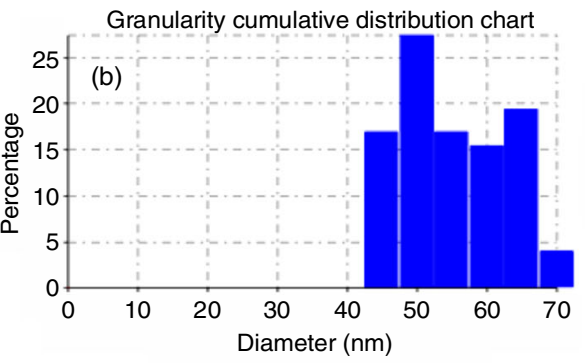

Granularity cumulative distribution chart

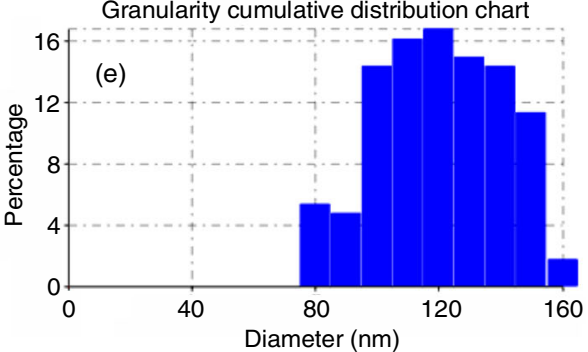

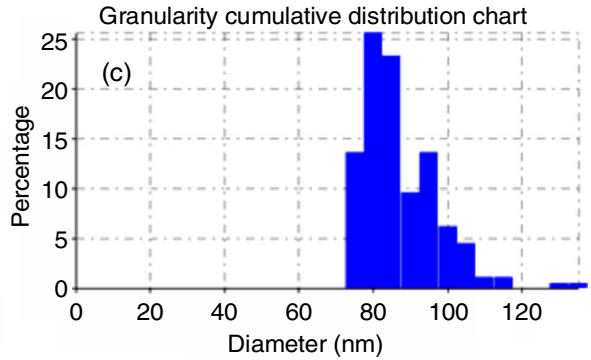

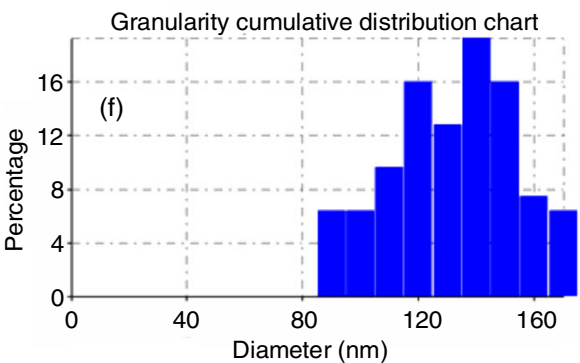

Fig. 7. Granularity cumulation distribution for (a) CNTs, (b) $\mathrm{TiO}_{2}$ and (c-f) different ratio of $\mathrm{TiO}_{2} / \mathrm{CNT}$ composites, C (25:1), d (50:1), e (75:1), f (100:1) 


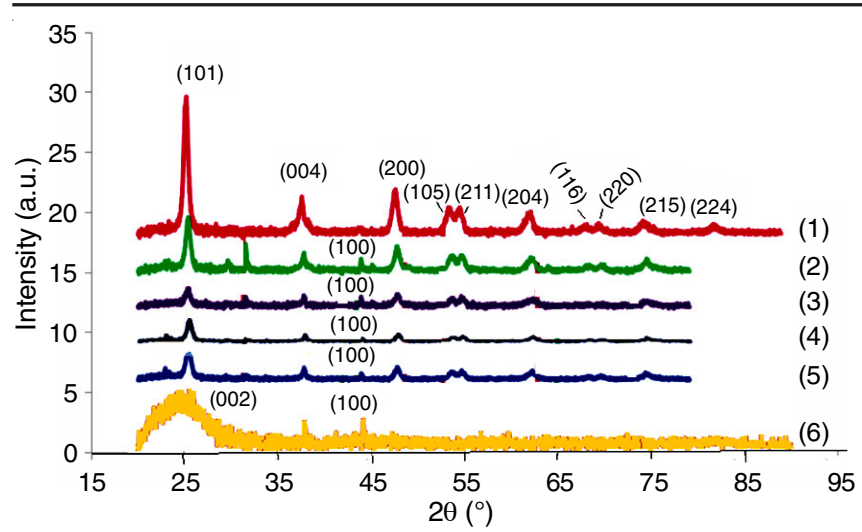

Fig. 8. XRD patterns for synthesized (6) CNTs, (1) $\mathrm{TiO}_{2}$ and (2-5) different ratio of $\mathrm{TiO}_{2} / \mathrm{CNTs}$ composites

$54.91^{\circ}(211), 62.50^{\circ}(204), 70.00^{\circ}(116), 70.89^{\circ}(220) 75.16^{\circ}$ (301). The additional peaks present in all the diffractograms agree to the $\mathrm{TiO}_{2}$ form of $\mathrm{TiO}_{2}$. The peak at $24.56^{\circ}(002)$ reflection due to CNTs intersections in the $\mathrm{TiO}_{2} 25.33^{\circ}$ (101) reflection. It is worth to notice that the intensity of $\mathrm{TiO}_{2}$ diffraction peaks increases from sample (1 to 5) and the width at half height of the peaks decreases. This is consistent with the increasing amount of $\mathrm{TiO}_{2}$ from samples 2 to 5 , which gives more stretched crystallized areas on the surface. The composite shows all these above points out peaks promotes the formation of $\mathrm{TiO}_{2} / \mathrm{CNTs}$ composite.

Mechanism of enhancement of photocatalysis of CA dye over $\mathrm{CNTs} / \mathrm{TiO}_{2}$ composite: Mechanism for removal of cobalamin dye over $\mathrm{CNTs} / \mathrm{TiO}_{2}$ composite and neat components of each of $\mathrm{TiO}_{2}$ and CNTs are shown in Fig. 9. Upon light irradiation of composite photocatalyst conduction band electron $\left(\mathrm{CB}^{-}\right)$and valence band hole $\left(\mathrm{VB}^{+}\right)$pairs can be produced. It is believed that carbon nanotub can behave as an electron entrapment and part of photo-produced electrons in $\mathrm{CB}^{-}$of $\mathrm{TiO}_{2}$ are rapidly can be injected to carbon nanotubs and the photogenerated charge carriers under these circumstances are excellently separated as explained in the following equations:

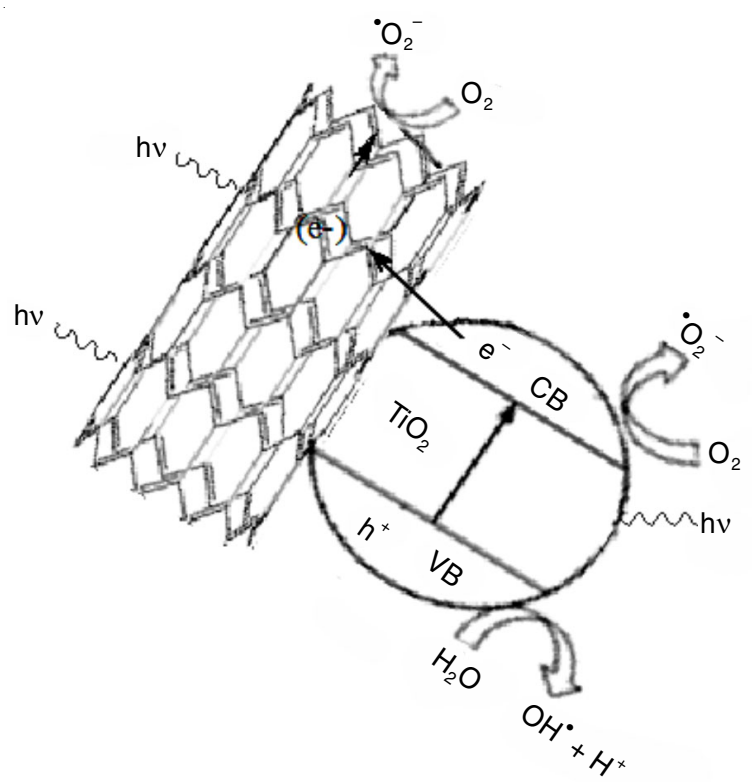

Fig. 9. Schematic description of a proposed model for the $\mathrm{CNT} / \mathrm{TiO}_{2}$ working mechanism

$$
\begin{gathered}
\mathrm{CNT} / \mathrm{TiO}_{2}+\mathrm{h}^{+} \longrightarrow \mathrm{CNT} / \mathrm{TiO}_{2}\left(\mathrm{e}^{-}+\mathrm{h}^{+}\right) \\
\mathrm{CNT} / \mathrm{TiO}_{2}\left(\mathrm{e}^{-}+\mathrm{h}^{+}\right) \longrightarrow \mathrm{CNT}\left(\mathrm{e}^{-}\right)+\mathrm{TiO}_{2}\left(\mathrm{~h}^{+}\right) \\
\mathrm{CNT}\left(\mathrm{e}^{-}\right)+\mathrm{O}_{2} \longrightarrow \mathrm{CNT}+\mathrm{O}_{2}^{--} \\
\mathrm{TiO}_{2}\left(\mathrm{~h}^{+}\right)+\mathrm{H}_{2} \mathrm{O} \longrightarrow \mathrm{TiO}_{2}+\mathrm{OH}^{\bullet} \\
\mathrm{O}_{2}{ }^{-}+\mathrm{OH}^{\bullet}+\text { Cobalamin dye } \longrightarrow \\
\text { Intermediate products } \longrightarrow \mathrm{CO}_{2}+\mathrm{H}_{2} \mathrm{O}
\end{gathered}
$$

They produced highly reactive $\mathrm{O}_{2}{ }^{--}$and $\mathrm{OH}^{\bullet}$ radicals degrade the cobalamin dye to form several intermediates and finally the formed intermediates into $\mathrm{CO}_{2}$ and $\mathrm{H}_{2} \mathrm{O}$.

\section{Conclusion}

Titanium dioxide nanoparticles $\left(\mathrm{TiO}_{2}\right)$ anatase/CNTs composite photocatalysts with different ratios were prepared by a simple evaporation and drying process. The $\mathrm{TiO}_{2} / \mathrm{CNTs}$ (50:1) composite had higher activity of about four different ratios of $\mathrm{TiO}_{2} / \mathrm{CNTs}$ composites, $\mathrm{TiO}_{2}$ and CNTs. The CNTs with $\mathrm{TiO}_{2}$ had characterized the key of high efficiency for decolorization for cobalamin dye. The results indicate that the decolorzation efficiency percentage of cobalamin dye with $\mathrm{TiO}_{2} /$ CNTs composite was higher that titanium dioxide or CNTs. The efficiency of color removed increase with time. The removal efficiency of cobalamin was found to be $97 \%$. The results show that the photocatalytic activity of different ratios in this study was 50:1 75:1 100:1 25:1 $>$ CNTs $>\mathrm{TiO}_{2}$. This result can be attributed due to the improvement of catalytic properties and increment of specific surface area of the prepared composites in comparison with their single components. The carbon nanotubes can increase surface area for synthesized composites and then reduce the rate of $(\mathrm{e}-\mathrm{h})$ recombination on $\mathrm{TiO}_{2}$.

\section{CONFLICT OF INTEREST}

The authors declare that there is no conflict of interests regarding the publication of this article.

\section{REFERENCES}

1. A. Aqel, K.M.M.A. El-Nour, R.A.A. Ammar and A. Al-Warthan, Arab. J. Chem., 5, 1 (2012); https://doi.org/10.1016/j.arabjc.2010.08.022.

2. C. Liu and H.-M. Cheng, Mater. Today, 16, 19 (2013); https://doi.org/10.1016/j.mattod.2013.01.019.

3. E. Del Canto, K. Flavin, D. Movia, C. Navio, C. Bittencourt and S. Giordani, Chem. Mater, 23, 67 (2011); https://doi.org/10.1021/cm101978m.

4. P. Mahalingam, B. Parasuram, T. Maiyalagan and S. Sundaram, J. Environ. Nanotechnol., 1, 53 (2012).

5. V.N. Popov, Mater. Sci. Eng., 43, 61 (2004); https://doi.org/10.1016/j.mser.2003.10.001.

6. T.-J. Park, S. Banerjee, T. Hemraj-Benny and S.S. Wong, J. Mater. Chem., 16, 141 (2006); https://doi.org/10.1039/B510858F.

7. G. Hu, X. Meng, X. Feng, Y. Ding, S. Zhang and M. Yang, J. Mater. Sci., 42, 7162 (2007);

https://doi.org/10.1007/s10853-007-1609-7.

8. K.D. Shitole, R.K. Nainani and P. Thakur, Def. Sci. J., 63, 435 (2013); https://doi.org/10.14429/dsj.63.4870.

9. H. Chen, S. Yang, K. Yu, Y. Ju and C. Sun, J. Phys. Chem., 115, 3034 (2011); https://doi.org/10.1021/jp109948n.

10. N. Bouazza, M. Ouzzine, M.A. Lillo-Rodenas, D. Eder and A. LinaresSolano, Appl. Catal. B, 92, 377 (2009); https://doi.org/10.1016/j.apcatb.2009.08.017. 
11. R. Leary and A. Westwood, Carbon, 49, 741 (2011); https://doi.org/10.1016/j.carbon.2010.10.010.

12. W. Wang, P. Serp, P. Kalck, C.G. Silva and J.L. Faria, Mater. Res. Bull., 43, 958 (2008) https://doi.org/10.1016/j.materresbull.2007.04.032.

13. M.-L. Chen, F.-J. Zhang and W.-C. Oh, New Carbon Mater, 24, 159 (2009);

https://doi.org/10.1016/S1872-5805(08)60045-1.

14. K. Woan, G. Pyrgiotakis and W. Sigmund, Adv. Mater, 21, 2233 (2009); https://doi.org/10.1002/adma.200802738.

15. M. Alsawat, T. Altalhi, K. Gulati, A. Santos and D. Losic, ACS Appl. Mater. Interfaces, 7, 28361 (2015); https://doi.org/10.1021/acsami.5b08956.

16. J. Safari and S. Gandomi-Ravandi, J. Mol. Struct., 1065-1066, 241 (2014); https://doi.org/10.1016/j.molstruc.2014.02.035.

17. M.H. Rümmeli, A. Bachmatiuk, F. Börrnert, F. Schäffel, I. Ibrahim, K. Cendrowski, G. Simha-Martynkova, D. Plachá, E. Borowiak-Palen, G. Cuniberti and B. Büchner, Nanoscale Res. Lett., 6, 303 (2011); https://doi.org/10.1186/1556-276X-6-303.
18. B. Liu, S. Lyu, S. Jung, H. Kang, C. Yang, J. Park, C. Park and C. Lee, Chem. Phys. Lett., 383, 104 (2004); https://doi.org/10.1016/j.cplett.2003.10.134.

19. A.M. Kamil, F.H. Hussein, A.F. Halbus and D.W. Bahnemann, Int. J. Photoenergy, Article ID 475713 (2014); https://doi.org/10.1155/2014/475713.

20. M. Ahmed, H.M.N. Iqbal and Z. Akram, Arab. J. Sci. Eng., 43, 23 (2018); https://doi.org/10.1007/s13369-017-2662-4.

21. A.M. Jassm, F.H. Hussein, F.H. Abdulrazzak, A.F. Alkaim and B.A. Joda, Asian J. Chem., 29, 2804 (2017); https://doi.org/10.14233/ajchem.2017.20994

22. B. Czech, P. Oleszczuk and A. Wiacek, Environ. Pollut., 200, 161 (2015); https://doi.org/10.1016/j.envpol.2015.02.020.

23. N.I. Kovtyukhova, T.E. Mallouk, L. Pan and E.C.J. Dickey, J. Am. Chem. Soc., 125, 9761 (2003); https://doi.org/10.1021/ja0344516.

24. Y. Yao, G. Li, S. Ciston, R.M. Lueptow and K.A. Gray, Sci. Technol., 42, 4952 (2008)

https://doi.org/10.1021/es800191n. 